\title{
Stability of Dental Composites in Water and Artificial Saliva
}

\author{
ANTARINIA CRACIUN ${ }^{1}$, DOINA PRODAN ${ }^{2 *}$, MARIANA CONSTANTINIUC ${ }^{\mathbf{1}}$, ANA ISPAS ${ }^{\mathbf{1}}$, \\ MIUTA FILIP ${ }^{2}$, MARIOARA MOLDOVAN ${ }^{2}$, MINDRA BADEA ${ }^{3}$, IOAN PETEAN ${ }^{4}$, \\ MARIA CRISAN ${ }^{5}$ \\ ${ }^{1}$ Iuliu Hatieganu University of Medicine and Pharmacy, Department of Prosthodontics and Dental Materials, 32 Clinicilor Str., 400006 \\ Cluj-Napoca, Romania \\ ${ }^{2}$ Babes-Bolyai University, Raluca Ripan Institute for Research in Chemistry, Department of Polymer Composites, 30 Fantanele Str., 400294 \\ Cluj-Napoca, Romania \\ ${ }^{3}$ Iuliu Hatieganu University of Medicine and Pharmacy, Department of Preventive Dental Medicine, 31 Avram Iancu Str., 400083 Cluj- \\ Napoca, Romania \\ ${ }^{4}$ Babes-Bolyai University, Faculty of Chemistry and Chemical Engineering, 11 Arany Janos Str., 400084, Cluj - Napoca, Romania \\ ${ }^{5}$ Iuliu Hatieganu University of Medicine and Pharmacy, Department of Dermatology, 1 Clinicilor Str., 400006, Cluj-Napoca, Romania
}

Abstract. The aim of this in vitro study was to evaluate the characteristics of four commercial dental composites: two dual-curing luting resin cements and two indirect composites for crowns and bridges. The novelty of the study consists in the use of combined characterization methods for the investigated materials, namely: after maintaining the samples in the water/ artificial saliva, besides sorption, the surface degradation of the samples was observed after their immersion period; thereafter, the immersion medium was lyophilized and then the percentage of residual monomer found in the medium was determined by HPLC. After 44 days, small concentrations of monomers have been determined in the aqueous/saliva extracts. SEM images show that the samples from each class of material, with a higher content of inorganic filler, exhibit a larger erosion of the surfaces after contact with water compared to the other two samples that show a larger erosion of surfaces after contact with saliva than with water. The surface of the dual-curing resin cement with a higher content of inorganic filler is the smoothest from the samples exposed to saliva, instead the other resin cement is the roughest, as shown by AFM analysis. The overall observation reveals that the samples kept in saliva are rougher than the ones kept in water. Smooth surface materials of both classes of materials ( with a higher content of inorganic filler) have absorbed a higher amount of water / saliva compared to materials with a rougher surface.Water sorption in the composite resins is influenced by the hydrophilicity of the monomers, the nature and size of the inorganic filler particles, and the quality of the matrix / filler interface.

Keywords: resin cements, indirect composites, water sorption, HPLC, SEM, AFM

\section{Introduction}

Adhesion and esthetics of resin based dental materials are the main features that recommend the use of composites on large-scale in dental medicine. Modifying the composition of resin luting agents played an important role for improving their properties. Upon contact with the liquids in the oral environment, an expansion of the organic matrix occurs due to the absorption phenomenon; this stress factor leads to the deformation of the resin-dentine bond, influencing the state of stress in the structure of the restored tooth [1]. The hygroscopic stress can cause micro-cracks or microfractures on the restored surface, due to hydrolytic degradation of bonds inside both the polymeric matrix and the resin-filler interface [2- 5].

Also, the resin polarity controls the speed and extent of water absorption in polymer networks. In fact, the water absorption of the resin is influenced by the chemical nature of the polymer relative to the water molecule. Water is absorbed into the polymer due to the polarity of polymer molecules, unsaturated molecule bonds, or unbalanced intermolecular forces in polymers [6]. However, the water sorption of restoration composite materials can have a positive effect offsetting the shrinkage of polymerization by relaxing the stress caused by it. On the other hand, significant hydroscopic expansion can become detrimental to the material [1]. The sorption may depend on the storage time and medium of the specimens $[4,7]$.

\footnotetext{
*email: doina_prodan@yahoo.com
} 
The novelty of the study consists in the use of combined characterization methods for four commercial dental composites: two dual-curing luting resin cements and two indirect composites for crown and bridgesin order to establish the material with the best properties. These materials were investigated by water/saliva sorption measurements, residual monomers (by high-performance liquid chromatography analysis - HPLC), and structure (by scanning electron microscopy- SEM and atomic force microscopy - AFM). The residual monomers investigated were urethane dimethacrylate (UDMA), triethylene glycol dimethacrylate (TEGDMA). The results of all tests were correlated with the water/ saliva sorption.

\section{Materials and methods}

\subsection{Materials}

The chemical composition of the investigated materials is shown in table 1.

Table 1 Materials investigated in this study

\begin{tabular}{|c|c|c|c|c|c|}
\hline Material/ use & $\begin{array}{l}\text { Manufac- } \\
\text { turer }\end{array}$ & Organic matrix & $\begin{array}{l}\text { Concen- } \\
\text { tration } \\
(\%)\end{array}$ & Inorganic filler & $\begin{array}{l}\text { Concen- } \\
\text { tration } \\
(\%)\end{array}$ \\
\hline $\begin{array}{l}\text { Sample 1: } \\
\text { SR Adoro, light-/heat- } \\
\text { curing veneering composite } \\
\text { for full-coverage and partial } \\
\text { veneer, metal-supported } \\
\text { and metal-free restorations }\end{array}$ & $\begin{array}{l}\text { Ivoclar } \\
\text { Vivadent }\end{array}$ & UDMA & 48 & $\begin{array}{l}\text { Glass with } \mathrm{Ba}, \mathrm{SiO}_{2}, \\
(\mu \mathrm{m}), \text { Stabilizers, } \\
\text { catalysts and pigments }\end{array}$ & 51 \\
\hline $\begin{array}{c}\text { Sample 2: } \\
\text { Variolink Esthetic DC, } \\
\text { Self-adhesive resin cement }\end{array}$ & $\begin{array}{l}\text { Ivoclar } \\
\text { Vivadent }\end{array}$ & $\begin{array}{l}\text { UDMA } \\
\text { and further } \\
\text { methacrylate } \\
\text { monomers. }\end{array}$ & 32 & $\begin{array}{c}\text { Ytterbium trifluoride, } \\
\text { spheroid mixed oxide, } \\
\text { particle size } 0.04-0.2 \mu \mathrm{m} . \\
\text { (mean particle size: } 0.1 \\
\mu \mathrm{m})\end{array}$ & 67 \\
\hline $\begin{array}{c}\text { Sample 3: } \\
\text { Solidex, Composite for } \\
\text { crowns and bridges on } \\
\text { metal frames }\end{array}$ & Shofu & UDMA & 47 & $\begin{array}{l}\text { Inorganic filler particle } \\
\text { range: } 0,16-7 \mu \mathrm{m}\end{array}$ & 53 \\
\hline $\begin{array}{c}\text { Sample 4: } \\
\text { *RelyX Unicem } \\
\text { Self-adhesive resin cement }\end{array}$ & 3M ESPE & $\begin{array}{l}\text { Methacrylate } \\
\text { monomers } \\
\text { containing } \\
\text { phosphoric acid } \\
\text { groups, } \\
\text { methacrylate } \\
\text { monomers }\end{array}$ & 30 & Silanated fillers & 70 \\
\hline
\end{tabular}

\section{Artificial saliva}

Artificial saliva was obtained in the laboratory, simulated the salt composition of saliva, according to the following recipe: $0.4 \mathrm{~g} / \mathrm{L} \mathrm{NaCl}, 0.4 \mathrm{~g} / \mathrm{L} \mathrm{KCl}, 0.795 \mathrm{~g} / \mathrm{L} \mathrm{CaCl} 2 \cdot 2 \mathrm{H} 2 \mathrm{O}, 0.69 \mathrm{~g} / \mathrm{L} \mathrm{NaH} \mathrm{PO}_{4} \cdot \mathrm{H}_{2} \mathrm{O}$, $0.005 \mathrm{~g} / 1 \mathrm{Na}_{2} \mathrm{~S} \cdot 9 \mathrm{H}_{2} \mathrm{O}$, and $1.0 \mathrm{~g} / \mathrm{L} \mathrm{CO}\left(\mathrm{NH}_{2}\right)_{2}$, aqueous solution [8].

\subsection{Characterization methods}

\subsubsection{Determination of water and artificial saliva sorption}

Determination of water/ saliva sorption was performed according to ISO 4049 [9]. Six disk specimens $(15 \times 1 \mathrm{~mm})$ were made from each material, using a teflon mold. Prior to weighing, the specimens were kept in a desiccator at $23^{\circ} \mathrm{C}$ until a constant mass, mi (initial mass) was obtained, after which they were immersed in $10 \mathrm{~mL}$ of distilled water and, in parallel, in artificial saliva, for a fixed period of time. For each material, the samples were divided into two groups (each group contains five discs) and stored at $37 \pm 1{ }^{\circ} \mathrm{C}$. Daily, the specimens were extracted from the water/ saliva, wiped and dried in air for $15 \mathrm{~s}$. After $5 \mathrm{~min}$, they were weighed, recording the final mass $\mathrm{mf}$ (final mass). 
The water / saliva sorption $\left(W_{s p}\right)$ value for each specimen was calculated using the formula:

$$
W_{s p}[\%]=\frac{\left(m_{f}-m_{i}\right)}{m_{i}} \times 100
$$

\subsubsection{HPLC determination of residual monomers Sample preparation}

After 44 days, the storage medium (water/artificial saliva) in which the samples were immersed in order to perform the sorption assay, were frozen and then lyophilized in a Model Alpha 1-4 LDPLUS lyophilizer until the liquid is completely removed. The residual monomers from restoration composites were determined from the lyophilized storage medium (water/ artificial saliva) and the residue was resuspended in $0.6 \mathrm{~mL}$ of acetonitrile, filtered in $0.22 \mu \mathrm{m}$ PTFE filters and analyzed by HPLC.

Instrumentation and method. The analyses were carried out on a High Performance Liquid Chromatograph equipped with an intelligent HPLC pump (PU-980, Jasco International Co., LTD., Tokyo, Japan), a ternary gradient unit, an intelligent column thermostat, an intelligent UV/VIS detector and an injection valve equipped with a $20 \mu \mathrm{L}$ sample loop (Rheodyne). Separation was carried out on a Lichrosorb RP-C18 column $(25 \times 0.46 \mathrm{~cm})$ at $21{ }^{\circ} \mathrm{C}$ column temperature. The mobile phase was a mixture of acetonitrile (A, HPLC grade) and water (Milipore ultrapure water) and a gradient applied was: 0 - $15 \mathrm{~min}$, linear gradient from $50 \%$ to $80 \% \mathrm{~A} ; 15-25 \mathrm{~min}$, linear gradient from 80 to $50 \% \mathrm{~A}$. The flow rate was $0.9 \mathrm{~mL} \cdot \mathrm{min}-1$ and the injector volume was always $20 \mu \mathrm{L}$. UV detection was performed at $204 \mathrm{~nm}$ for monitoring the elution of all standards (Bis-GMA, TEGDMA and UDMA). The linearity of the response to analyses was established with four concentration levels and the regression factors R2 were $>0.998$.

\subsubsection{Microstructural analysis of composites surfaces}

The structure of representative sample surfaces for each investigated composite material, before and after storage in distilled water/ artificial saliva after a 44-day period, was performed by electronic scanning microscopy (SEM-Inspect S, FEI).

\subsubsection{Atomic force microscopy (AFM)}

The atomic force microscopy (AFM) was performed on a JEOL JSPM 4210 Scanning Probe Microscope, Japan. The topographic images were recorded in tapping mode using NSC 15 cantilevers produced by Micromasch Co. Bulgaria (resonant frequency $325 \mathrm{kHz}$ and force constant $40 \mathrm{~N} / \mathrm{m}$ ). All images were scanned at an area of $5 \mu \mathrm{m} \times 5 \mu \mathrm{m}$ at a scan rate of about $1 \mathrm{~Hz}$. The AFM topographic images were processed using WinSPM 2.0 Processing soft powered by JEOL for the AFM microscopes. There were investigated the surface morphology and roughness. For each material were scanned at least 3 different macroscopic zones to achieve the average Ra.

\section{Results and discussions}

\subsection{Determination of water and artificial saliva sorption for studied composites}

The mean values and standard deviations of sorption characteristics for the composite materials after immersion in water and artificial saliva are presented graphically in Figures 1 and 2. 


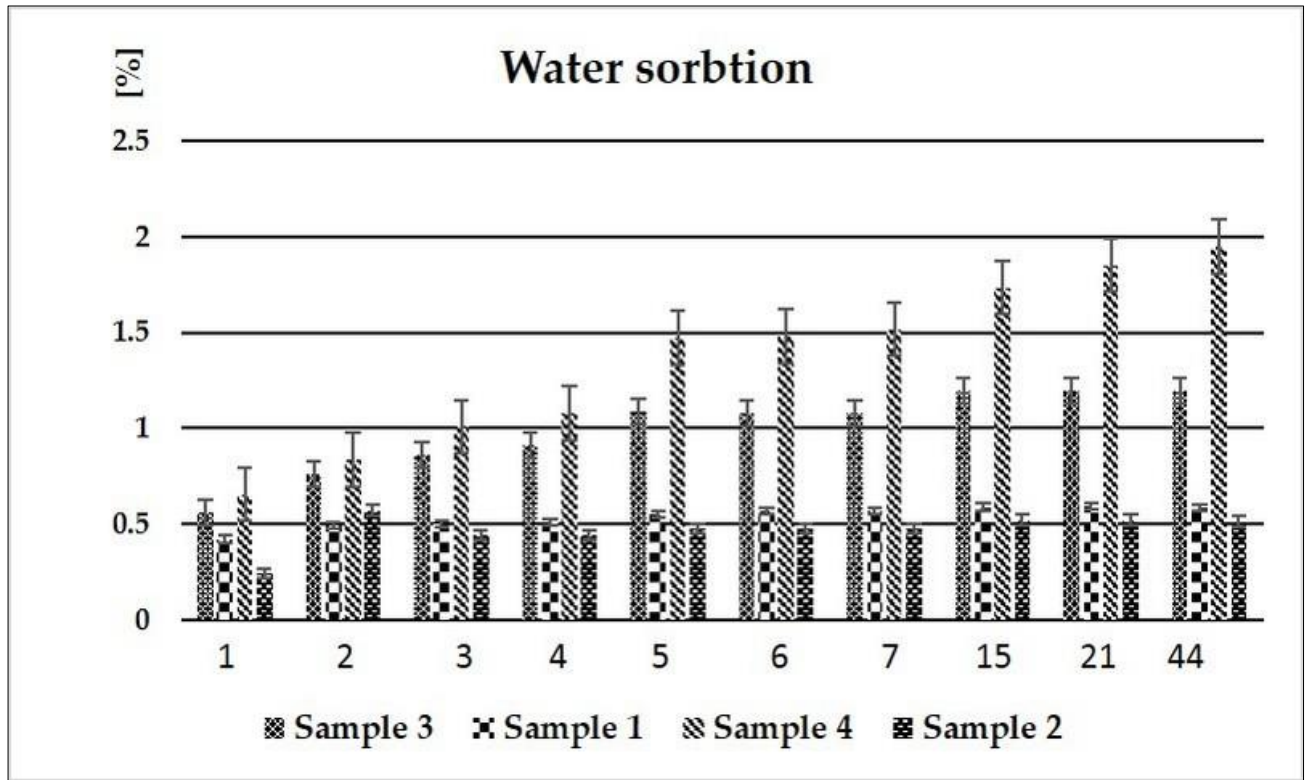

Figure 1. The variation in time of the percentages of water sorption for each studied composite

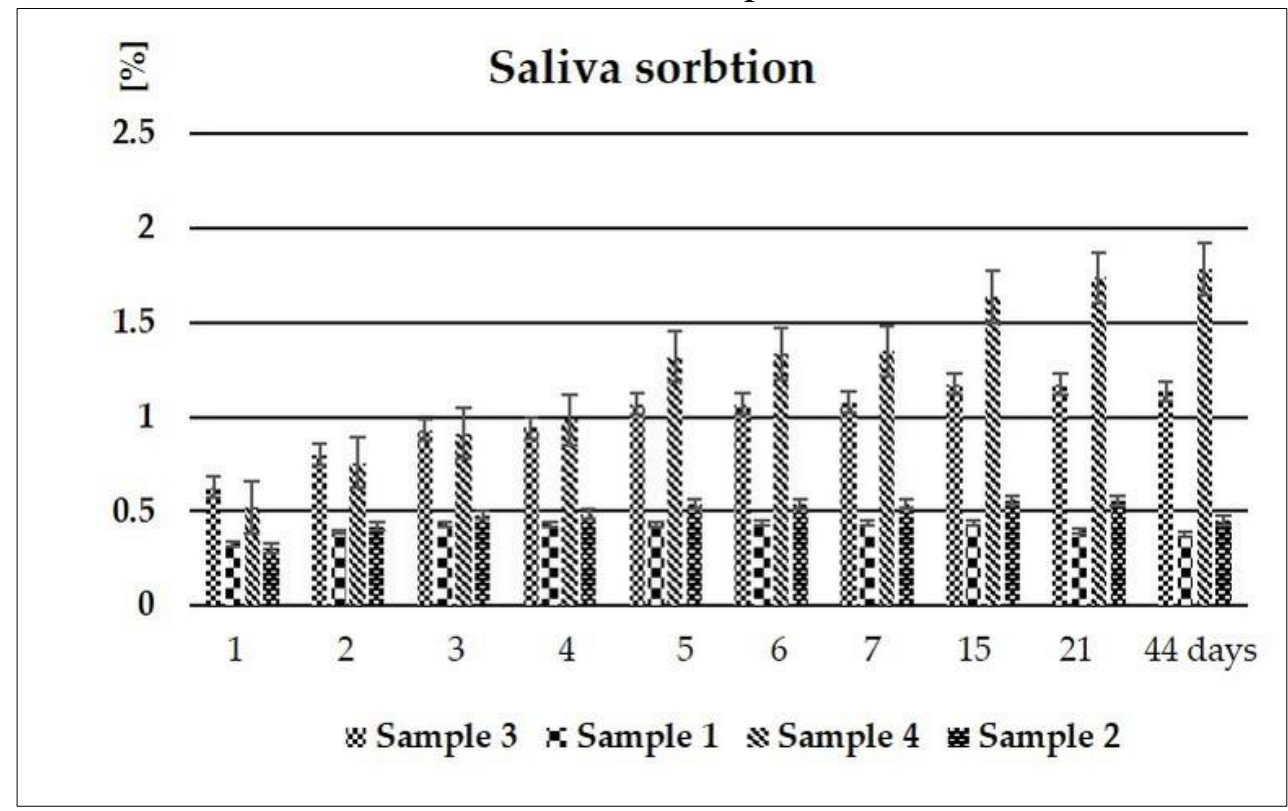

Figure 2. The variation in time of the percentages of artificial saliva sorption for each studied composite

Water plays an important role in the chemical degradation of composite materials. By storing in water, the hydrolysis reaction and respectively, the swelling of the material take place. According to many researchers, water absorption takes place in the resin matrix of composite materials and is controlled by diffusion [4, 10-12]. Therefore, the diffusion coefficient decreases as the amount of water absorbed increases and as the storage period increases, the absorption rate decreases. The concentration of water absorbed depends on the amount of hydroxyl groups in the matrix that forms the hydrogen bonds with water. For example, TEGDMA monomer does not contain any hydroxyl group but has a certain affinity for water due to the water-compatible ether binding mode within the molecule [10, 12].

UDMA composites are less hydrophilic than Bis-GMA-based composites. Some researchers suggest that the main difference between UDMA and Bis-GMA is their flexibility. Therefore, systems containing carboxylic (acid) or phosphate groups as functional monomers are more hydrophilic than the resins containing the Bis-GMA / TEGDMA monomer system [10, 13]. 
Also, Braden and Clarke (1984) found that composite materials with a low inorganic filler content, respectively with a higher resin content, absorb more water than those with a higher degree of filler content $[10,11]$.

Figures 1-2 shows the variation in time of the percentages of water/ saliva sorption for each studied composite materials.

Sample 3 (Figure 1) showed after one day $0.56 \%$ water absorption; after 44 days, compared to the first day, absorption increased by $0.63 \%$. The sample 1 absorption after one day was $0.42 \%$; the water absorption recorded on day 44 compared to the first day increased by $0.16 \%$. The sample 4 sorption after one day was $0.65 \%$; it can also be observed that the percentage of the absorbed water increases throughout the investigation period of this sample. Therefore, after 44 days, as compared to the first day, absorption increased by $1.29 \%$. The sample 2 sorption after one day water was $0.24 \%$, being the smallest percentage of water absorbed compared to the other materials studied; after 44 days, as compared to the first day, sorption increased by $0.26 \%$. About this material, the manufacturer informs that the interaction between the spherical filler particles and the monomer mixture provides the necessary fluidity, giving it a flexible, controlled consistency depending on the situation for which it is applied. It contains monomers with low viscosity, whose hydrophilic / hydrophobic properties have been adjusted to ensure optimum wetting of the filler materials. Therefore, in order to allow the incorporation of a higher filler content, comparable to other composite cements, low particle powders were used in the low viscosity monomers mixture [14].

Saliva sorption of the sample 3 (Figure 2) after one day was $0.62 \%$; after 44 days, compared to the first day, absorption increased by $0.50 \%$. For the sample 1 , saliva sorption after one day, was $0.32 \%$; after 44 days, compared to the first day, the absorption increased by $0.05 \%$. In the case of sample 4 , saliva absorption after one day was $0.52 \%$; the percentage of the absorbed saliva increases throughout the investigation period and after 44 days, as compared to the first day the absorption increased by $1.26 \%$. Regarding the sample 2, artificial saliva absorption after one day was $0.30 \%$, the lowest percentage of the absorbed saliva recorded compared to the the rest of the study materials; after 44 days, compared to day 1 , absorption increased by $0.14 \%$.

It is noted that: in artificial saliva, after one day of immersion, the highest absorption value was recorded for the sample 3 followed by sample 4, but after 44 days, the highest absorption value was recorded for the sample 4 followed by sample 3 . In terms of water sorption, the highest values are also recorded for sample 3 and sample 4, but after one day of immersion, in reverse order compared to artificial saliva absorption.

So, after 44 days, the lowest water sorption was recorded for the sample 2 followed by the samples 1,3 and 4, respectively. Regarding the absorption of artificial saliva, after 44 days, the lowest absorption was recorded for the sample 1 followed by the samples 2, 3 and 4, respectively. Therefore, the samples 1 and 3 of composite materials (Table 1) have in their composition a higher percentage of the organic matrix components than the other two composites, respectively the samples 4 and 2 . It is assumed that the water / saliva absorption should be higher for the first two materials. From our experiment, the highest percentages of absorption were recorded for the sample 4 (with the lowest organic matrix concentration) and the sample 3. For the sample 4, the acidic nature of the phosphorylated methacrylate can cause erosion of surfaces of samples tested by us due to hydrolysis of the methacrylate ester bond in water [15]. The sample 1 showed a low percentage of water absorption and the lowest percentage of saliva absorption compared to the other investigated materials.

The water sorbtion is increased by the presence of the metallic ions in the filler, due to ion exchange. For instance, some ions, such as zinc and barium, in the filler powder, are electropositive and can to react with water. If the silanization of the filling is not performed correctly, upon contact with water, with the increase of the concentration of hydroxyl groups, the siloxane bonds in the silica network tend to break. Thus explaining the softening of the specimen surface over time $[16,17]$. 
3.2. HPLC determination of residual monomers from the composites extracts.

Based on calibration curves and HPLC chromatograms, the amounts of monomers extracted in water and in artificial saliva from reinforced restoration composites (Figures 3-5, Table 2) were determined.
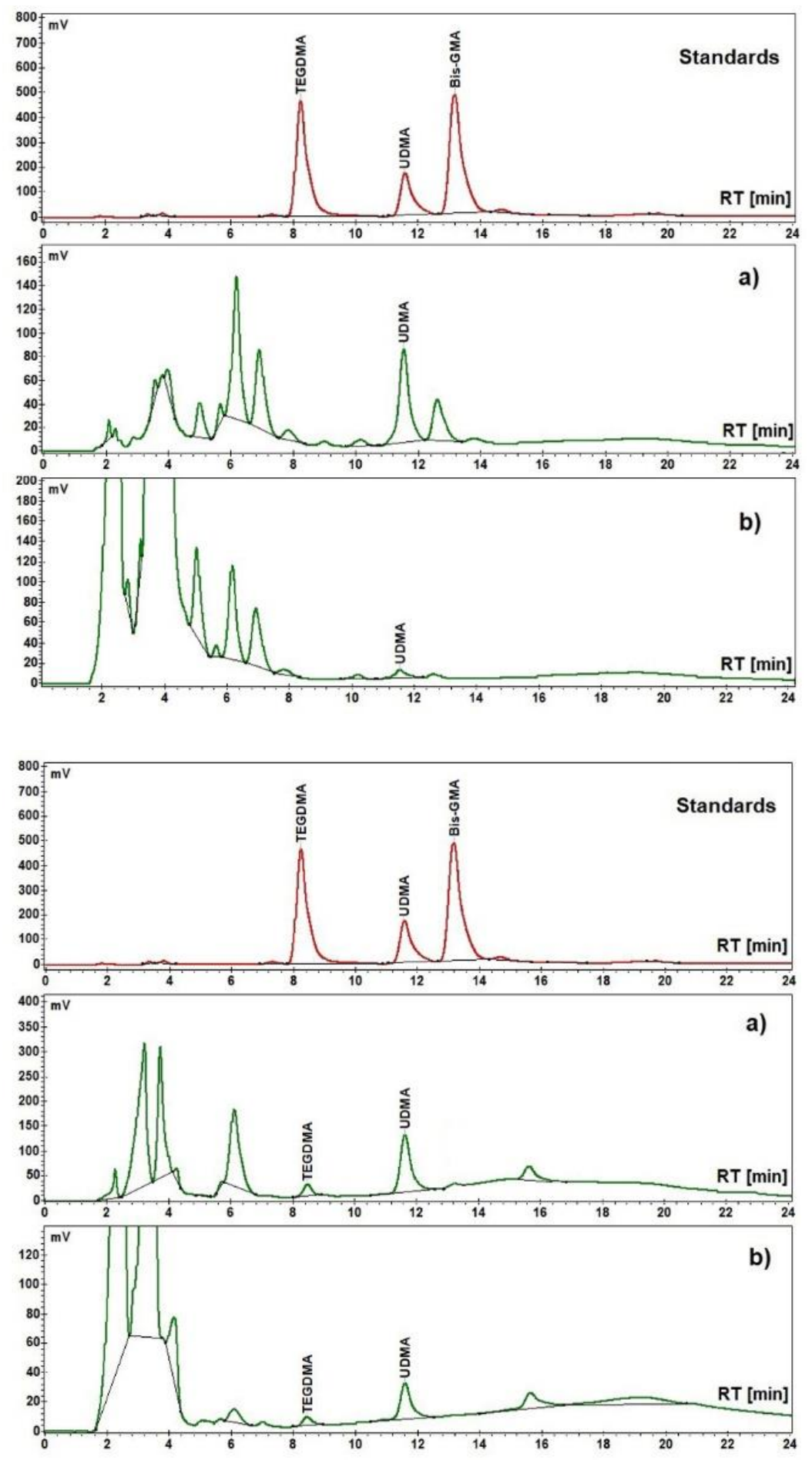

Figure 3. HPLC

chromatograms of standards and Sample 1 composite extracts in a) water and b) artificial saliva of samples.
Figure 4. HPLC

chromatograms of standards and Sample 3 composite extracts in a) water and b) artificial saliva. 

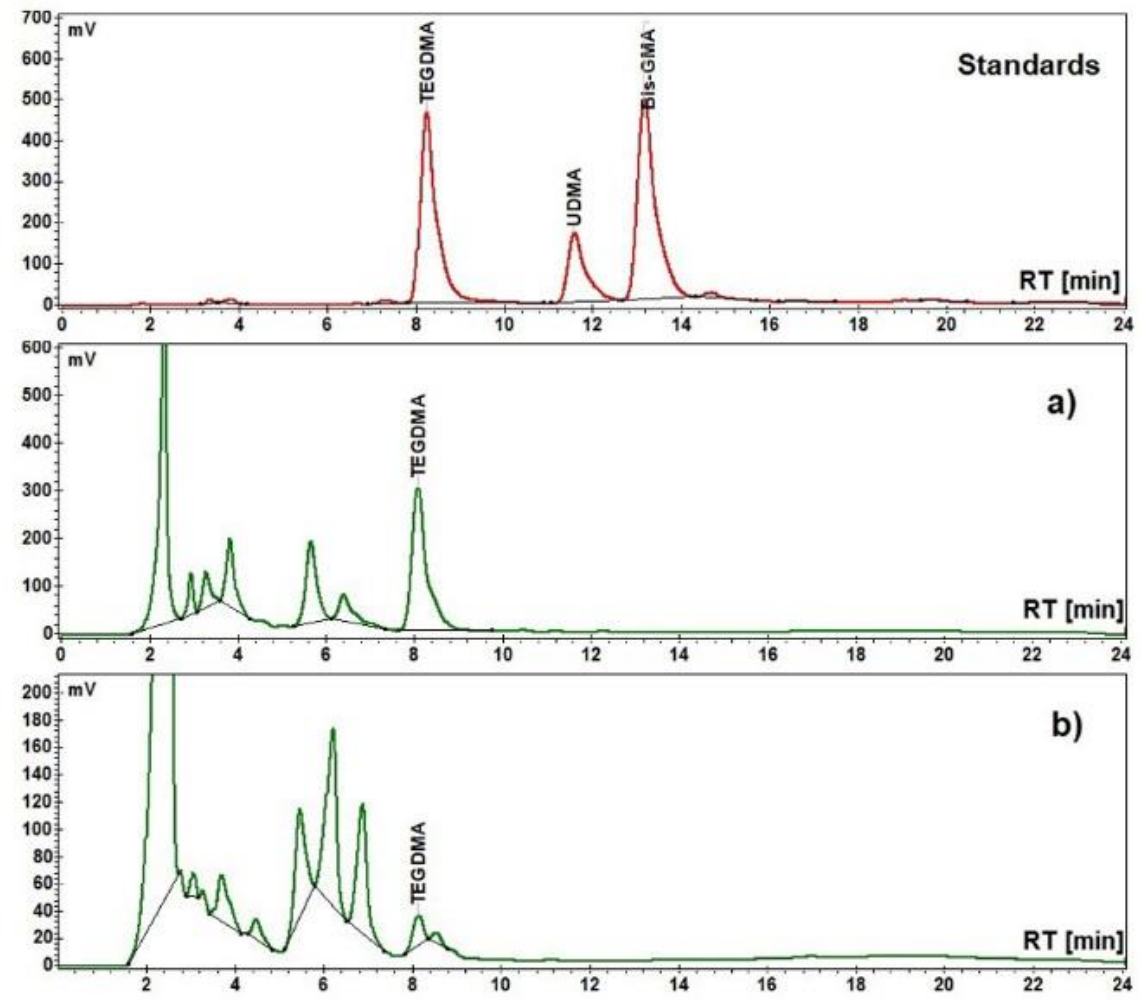

Figure 5. HPLC chromatograms of standards and Sample 4 composite extracts in

a) water and b) in artificial saliva of samples.

Table 2. Concentration of residual monomers for the investigated composites extracted in water and in artificial saliva

\begin{tabular}{ccccc}
\hline Sample name & Extract & TEGDMA [\%] & UDMA [\%] & Total \\
\hline Sample 1 & water & - & 0.0010 & 0.0010 \\
\hline Sample 1 & saliva & - & 0.00014 & 0.00014 \\
\hline Sample 2 & water & 0.00007 & 0.0018 & 0.00187 \\
\hline Sample 2 & saliva & - & - & 0 \\
\hline Sample 3 & water & 0.00009 & 0.0015 & 0.0016 \\
\hline Sample 3 & saliva & 0.00002 & 0.00022 & 0.00024 \\
\hline Sample 4 & water & 0.0016 & - & 0.0016 \\
\hline Sample 4 & saliva & 0.00013 & - & 0.00013
\end{tabular}

Small molecules of the TEGDMA type in the organic matrix of the composite material being more mobile can be eluted more rapidly compared to higher weight molecules [10]. In our study, after 44 days, TEGDMA was found in both aqueous and saliva extracts in small concentrations in the samples 3 and 4 and in the aqueous extract in the sample 2.

According to Muèller et al. (1997), from an organic matrix with 50 wt\% TEGDMA, in case of BisGMA / TEGDMA-based composite, a double amount of TEGDMA is released than from an UEDMA / TEGDMA composite. According to monomers structure, Muèller explains that some molecules that are smaller (TEGDMA), with fewer polar groups and shorter pendant groups, may able to diffuse easier through the polymer network than larger monomer molecules (UDMA, Bis-GMA) [18]. In our study, after 44 days, UEDMA was found in both aqueous and saliva extracts in small concentrations in the samples of materials 3 and 1 and in the aqueous extract in the sample 2.

Table 2 shows that for the samples 4, 1, and 3, after a 44-day of the investigation period, the percentage value (total) of the residual monomer extracted into the saliva is ten times lower than that extracted in water. The lowest concentration of residual monomer, extracted in water, was detected for the sample 1, followed by the samples 4, 3 and 2. In artificial saliva, the sample 2, did not show any 
trace of residual monomer extracted from the two monomers. Low concentrations of residual monomer extracted in saliva were determined in the samples 4 and 1 and in the sample 3, a slightly higher.

The chromatograms (Figures 3-5) and table 2 show that the only residual monomer extracted in both water and saliva from the sample 1 was UDMA, while from the sample 4 it was extracted only TEGDMA. In their studies, Chaves et al. have shown that materials with higher water absorption do not necessarily have a high solubility and vice versa. Therefore, they have shown that less hydrophilic resins have higher solubility than more hydrophilic resins [19].

\subsection{Microstructural analysis of composites surfaces before and after absorption by SEM}

Figure 6 reveals the surface structure of studied samples which was performed by SEM using a magnification of 1000; initial images a), d), g) si j); images after water sorption b), e), h), and k); images after saliva absorption c), f), i) si l).
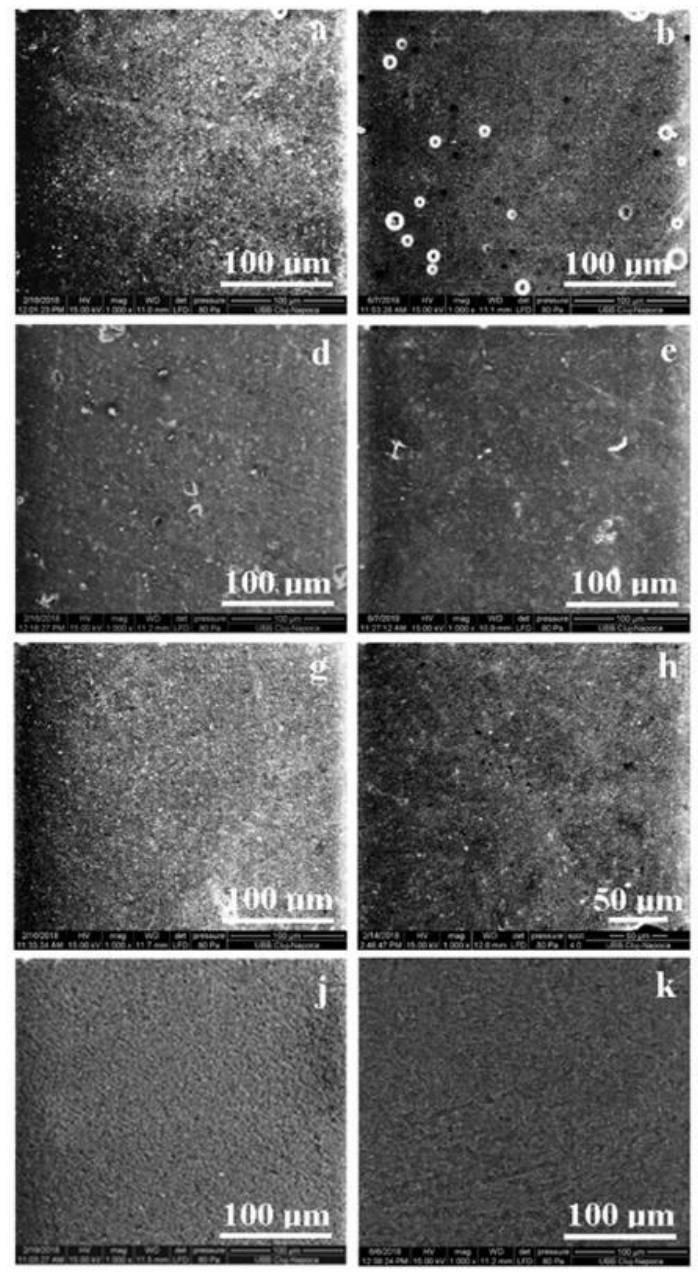
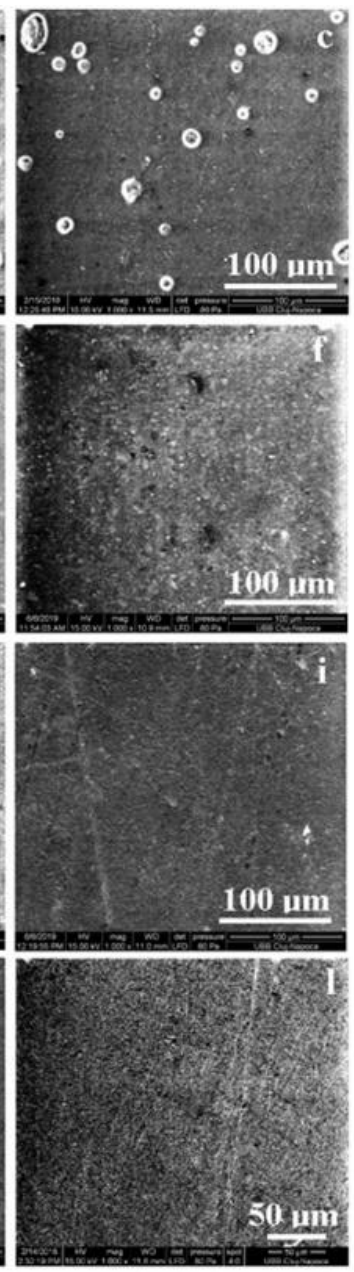

Figure 6. SEM images of the investigated materials:

a) Sample 3 initial, b) Sample 3 after water storage, c) Sample 3 after saliva storage;

d) Sample 1 initial , e) Sample 1 after water storage, f) Sample 1 after saliva storage;

g) Sample 4 initial, h) Sample 4 after water storage, i) Sample 4 after saliva storage;

j) Sample 2 initial, k) Sample 2 after water storage, and 1)

Sample 2 after saliva storage; The acquisition magnitude for all images is at 1000

SEM images demonstrate the differences between the surface structure of the initial samples (before immersion in the storage medium) and after a period of 44 days of storage in distilled water / artificial saliva. For the sample 3 (Figure 6. b-c), there are large gaps, formed by breaking of surface air bubbles incorporated in the mixing process of the material prior to polymerization. Gradually the water / saliva managed to penetrate inside these bubbles, causing particles to detach from the surface of the material. Both the samples 3 and 4 (Figure 6. b, h) show a larger erosion of the surfaces after contact with water than with saliva. The samples 1 and 2 (Figure 6. f, l) show a larger erosion of surfaces after contact with saliva than with water. 


\subsection{Atomic force microscopy (AFM)}

The most representative AFM topographic images obtained are presented in Figure 7.

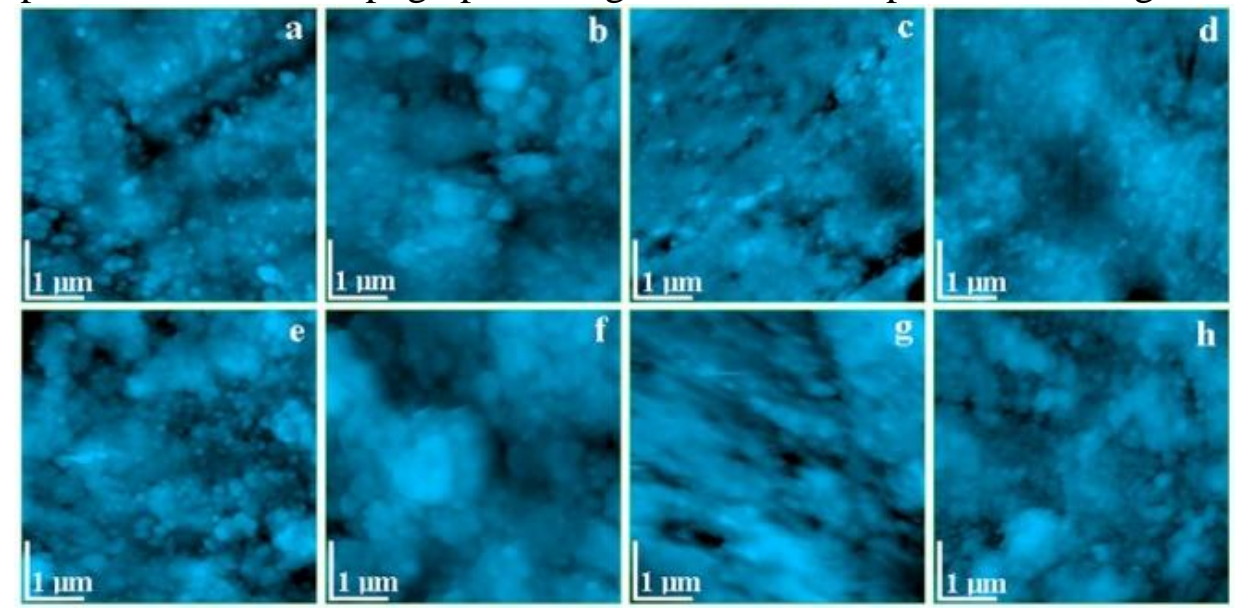

Figure 7. AFM topographic images for materials exposed to water:

a) Sample 1, b) Sample 2, c) Sample 4, d) Sample 3, and materials exposed to saliva:

e) Sample 1, f) Sample 2, g) Sample 4, h) Sample 3. Scanned area: $5 \mu \mathrm{m}$ x $5 \mu \mathrm{m}$.

Table 3. Ra average roughness obtained from afm investigation

\begin{tabular}{|c|c|c|c|c|}
\hline \multirow{2}{*}{$\begin{array}{c}\text { Exposure } \\
\text { environment }\end{array}$} & \multicolumn{4}{|c|}{$R a, n m$} \\
\hline & Sample 1 & Sample 2 & Sample 3 & Sample 4 \\
\hline Water & 27.30 & 91.40 & 17.10 & 11.53 \\
\hline Saliva & 30.70 & 136.00 & 24.06 & 23.3 \\
\hline
\end{tabular}

AFM is one of the most important techniques used for investigation of dental structures surfaces in contact with several environments. Data in literature shows that AFM proves the enamel decaying due to the acidic conditions [20,21]. It features the morphology and roughness changes during the erosion process. If AFM is suitable for tooth enamel it fits to investigate the surface of various materials destined to dental applications. We expect to observe the behavior of the materials in the present paper exposed for a significant period of time into the water and saliva.

The materials exposed to water, (Figure $7 \mathrm{a}-\mathrm{d}$ ), have a well-structured surface showing a compact mass formed by nanostructured grains stack together. The sample 1 grains have a diameter around 80 $\mathrm{nm}$. The sample 2 features a more complex morphology based on grains having $60-80 \mathrm{~nm}$ stacked into submicron clusters having an average diameter of $300 \mathrm{~nm}$. The sample 4 surface features the finest grains situated around $40 \mathrm{~nm}$ and a very good compactness. The sample 3 has nanograins with a diameter about $60 \mathrm{~nm}$. The prolonged contact of materials surfaces with water leads to a specific roughness, the average values resulted for each material are presented in Table 3. The sample 4 has the smoothest surface, followed closely by the sample 3 . The roughest surface results are for the sample 2 .

The images for materials exposed to saliva are presented in Figure $7 \mathrm{e}-\mathrm{f}$. the samples 1, 2 and 3 surfaces present erosion marks. Several nanograins from the surface were unlocked from the surface and were washed out by the saliva. The erosion forms two topographic layers. The higher one contains the reminiscence of the outer most layer of the initial surface, having washout shape. The lower layer is the newly - fresh formed surface, which has a morphology similar with the one observed in water exposure.

The sample 4 exposed to saliva leads to an intriguing behavior (Figure $7 \mathrm{~g}$ ). The surface is very washout and catchy for the cantilever's tip proving a strong tip-sample adhesion. It is due to the material surface modification having a pseudo- gelification tendency in the prolonged contact with the saliva. Thus the sample 4 surface is the smoothest from all the samples exposed to saliva and the Variolink is the roughest (Table 3). The overall observation reveals that the samples kept in saliva are rougher than the ones kept in water. 


\section{Conclusions}

Basically, the water sorption in the composite resins is influenced by the hydrophilicity of the monomers in the organic matrix, the nature and size of the inorganic filler particles, and the quality of the matrix / filler interface.

Since the organic matrix may contain micro or macropores, air bubbles embedded in the mixing step prior to polymerization, and free spaces between the crosslinked polymers chains, sometimes the water can be absorbed without altering the material volume. Otherwise, there is a swelling of the material due to the hydrophilicity of the some monomers. In our study, after 44 days, small concentrations of TEGDMA and UDMA monomers have been determined in the aqueous/saliva extracts.

\section{References}

1. SOKOLOWSKI, G., SZCZESIO, A., BOCIONG, K., KALUZINSKA, K., LAPINSKA, B., SOKOLOWSKI, J., DOMARECKA, M., LUKOMSKA-SZYMANSKA, M., Materials 11, 2018, p. 973.

2. GAVRANOVIĆ-GLAMOČ, A., AJANOVIĆ, S., KORAĆ, M., ZUKIĆ, S., STRUJIĆ-POROVIĆ, S., KAMBERĆESIR, A., KAZAZIĆ, L., BERHAMOVIĆ, E., Acta Med. Acad. 46, 2017, p. 124-132.

3. TAVANGAR, M., JAFARPUR, D., BAGHERI, R. J., Dent Biomater, 4, 2017, p. 387-393.

4. PATROI, D. N., MOLdOVAN, M., MitARIU, I. S. C., HANCU, V., COMANEANU, R. M., COMAN, C., BARBU, H. M., Mater. Plast., 53, 2016, 646-652

5. MANSO A.P., CARVALHO R.M., Dent Clin North Am., 61, 2017, p. 821-834.

6. FIGUERÔA, R.M.S., CONTERNO, B., ARRAIS C.A.G., SUGIO C.Y.C., URBAN V.M., NEPPELENBROEK K.H., J Appl Oral Sci., 26, 2018, p.7

7. BOBOIA, S., MOLDOVAN, M., PREJMEREAN C., SAROSI, C., ROMAN, A., ARDELEAN I., Mater. Plast., 52, 2015, 104-108

8. DRUMMOND, J.L., ANDRONOVA, K., AL-TURKI, L.I., SLAUGHTER, L.D., J. Biomed. Mater. Res. 71B, 2004, p. $172-180$

9. ***Dentistry - Polymer-based filling, restorative and luting materials. International Standard

Organization, ISO 4049, 2000

10. ORTENGREN, U., WELLENDORF, H., KARLSSON, S., RUYTER I.E., J Oral Rehabil. 28, 2001, p. 1106-1115.

11. BRADEN, M., CLARKE, R.L., I Proprietary Materials. Biomaterials, 5, 1984, p. 369.

12. MORTIER, E., GERDOLLE, D.A., DAHOUN, A., PANIGHI, M.M., Am. J. Dent., 18, 2005, p. 177-81.

13. BOCIONG, K., SZCZESIO, A., SOKOLOWSKI, K., DOMARECKA, M., SOKOLOWSKI, J., KRASOWSKI, M., LUKOMSKA-SZYMANSKA, M., Materials, 10, 2017, p. 1142.

14. ***https://www.ivoclarvivadent.ro/ro/documentatie-stiintifica/\#V

Variolink+Esthetic+-+Ivoclar+Vivadent+Report+No-+22 (27.05.2019)

15. LIU, W., MENG, H., SUN, Z., JIANG, R., DONG, C.A., ZHANG. C., Exp. Ther. Med., 15, 2018, p. 4531-4537.

16. .MARTOS, J., OSINAGA, P.W.R., OLIVEIRA, E, CASTRO, L.A.S., Mat. Res., 6, 2003, p. 599-604.

17. ZHOU, M., DRUMMOND, J.L.; HANLEY, L., Dent. Mat., 21, 2005, p. 145-155.

18. MÜLLER, H., OLSSON, S., SÖDERHOLM, K.J., Eur J Oral Sci., 105, 1997, p. 362- 362.

19.CHAVES L.P., GRACIANO, F.M.O., JÚNIOR, O.B., DOVALE PEDREIRA, A.P.R., MANSO, A.P., WANG L., Braz. Dent. Sci., 15, 2013, p. 29-35.

20. CERCI, B.B., ROMAN, L.S., GUARIZA-FILHO, O., CAMARGO, E.S., TANAKA O.M., Eur. J. Gen. Dent., 1, 2012, p. 187-191.

21. POGGIO, C., CECI, M., BELTRAMI, R., LOMBARDINI, M., COLOMBO, M., Ann Stomatol (Roma)., 5, 2014, p. 98-102.

$\overline{\text { Manuscript received: } 18.02 .202}$ 